\title{
Para entender la crisis económica en España. El círculo vicioso de la moneda única y la carencia de un modelo productivo eficiente
}

\author{
Understanding The Economic Crisis In Spain. The Vicious Cycle \\ of the Single Currency and the Lack of an Efficient Productive Model
}

\author{
Santos Miguel Ruesga Benito \\ Catedrático de Economía Aplicada, \\ Universidad Autónoma de Madrid \\ $<<$ ruesga@uam.es>>
}

Journal of Economic Literature

JEL:

F02, G15, O52

Palabras clave:

Integración económica,

Mercados financieros internacionales,

Europa

Keywords:

Economic Integration

International Financial Markets

Europe

\section{Resumen}

Para caracterizar la crisis económica española, resulta preciso analizar tanto los condicionante que implica, y las consecuencias de su pertenencia a la Unión Económica y Monetaria, es decir, el área euro, por un lado, con las restricciones que introduce para hacer frente a los problemas de corto plazo en materia de financiación.

Y por otro, las propias características de la economía española que se enraízan en décadas pasadas y mas en particular en las características del propio sistema productivo que ponen de manifiesto la existencia de carencias de recursos competitivos para dar salida a la crisis en la que está inmersa.

Junto a ello, el artículo considera también las grandes líneas de la política económica desarrollada en el transcurso de la crisis, con graves deficiencias que han profundizado en la propia depresión sin atender a las carencias estructurales de la economía española.

\section{Abstract}

To characterize the Spanish economic crisis, it is necessary to analyse both the constraints involved, and the consequences of the Economic Union membership and monetary, that is, the euro area, on the one hand, with the restrictions that introduces to deal with the problems of the short-term funding.

And on the other the characteristics of the Spanish economy that take root in past decades and more particularly on the characteristics of the productive system that put manifest lack of competitive resources to exit the crisis in which it is immersed.

Along with this, the article also considers the broad lines of economic policy developed in the course of the crisis, with serious deficiencies that have deepened in the own depression without paying attention to the Spanish economy structural weaknesses. 


\section{Introducción}

Para cualquier foráneo resulta cuando menos complejo entender lo que ha ocurrido en la economía española en el último lustro. En un corto espacio de tiempo se ha pasado del "milagro español", de una economía que generaba más de la mitad del empleo anual creado en toda la Unión Europea, allá por los primeros años del presente siglo, a destruir casi $50 \%$ del total de empleo desaparecidos en este espacio económico tras las crisis de 2007.

Quizá los nacionales tampoco se han repuesto del impacto de este cambio dramático del acontecer en su economía, que les ha lleva a unas cifras de desempleo de 25\%, afectando a casi seis millones de personas, cifras desconocidas en toda su historia estadísticamente documentada.

Una parte de la explicación, quizá más bien del detonante de la crisis que aconteció en el año 2007, se encuentra en los avatares del crack financiero iniciado en Estados Unidos, en los corolarios de la crisis de las subprime y de las reacciones de desconfianza generalizada en todo el sistema financiero mundial que siguieron a la hecatombe de Lehman Brothers y otras entidades financieras estadounidenses, que arrastraron en corto espacio de tiempo a otras alemanas, holandesas o británicas, entre otras. Pero esto es solo el inicio del relato, el grueso de la narración de la profunda depresión por la que atraviesa al economía española transcurre ya a este lado del Atlántico, en el escenario de la Unión Monetaria y en el interior de sus fronteras económicas.

Sobre la primera cuestión, la crisis financiera internacional, se ha debatido ya in extenso así como sobre su evolución y su desarrollo futuro. Hay ya muchos lugares comunes, aunque también muchas diferencias, sobre el origen de la misma, sus efectos y sus artífices. No obstante, se está lejos aún de alcanzar un cierto grado de consenso para obtener una interpretación de orden teórico sobre la misma. Como es habitual entre los economistas, alcanzaremos no una sino dos o tres e incluso cuatro interpretaciones, posiblemente de carácter excluyente en algunos casos. La ciencia económica nunca ha sido un territorio homogéneo y las líneas de demarcación entre lo científico y lo ideológico en el campo de las ciencias sociales son cuando menos difusas (Cordera y Tello, 2010, 26).

Y la cuestión no es baladí, pues del diagnóstico que se establezca habrán de arrancar las propuestas de actuación, la combinación de instrumentos de política económica que han de tratar de poner freno al declive económico en el que estamos inmersos y, particularmente a la sangría de empleo que padece el mercado laboral español.

Tras estas consideraciones preliminares, el objeto de este artículo estriba en analizar la segunda cuestión indicada, las peculiaridades del caso español en la presente crisis económica y financiera iniciada en 2007, con el fin de establecer un esbozo de diagnóstico que permita vislumbrar un cuerpo de medidas de política adecuada a la situación actual, en orden a componer una senda de desarrollo sostenible.

\section{La crisis de la economía española. Una primera caracterización}

La crisis económica cumple ya más de cinco años y continúa su curso. A medida que el tiempo pasa se expande su capacidad de deterioro y con ello el grado de pesimismo y 
angustia de los ciudadanos que la padecen de forma directa, a través del desempleo, o indirecta, mediante el deterioro de rentas que experimenta su entorno familiar o social.

A modo de síntesis se puede seguir en el cuadro 1 la secuencia de hechos que están caracterizando esta Gran Depresión y que se ha ido desarrollando a lo largo del lustro 2007-2012, de forma particular en los países desarrollados y con especial énfasis en los países miembro de la Unión Europea (UE).

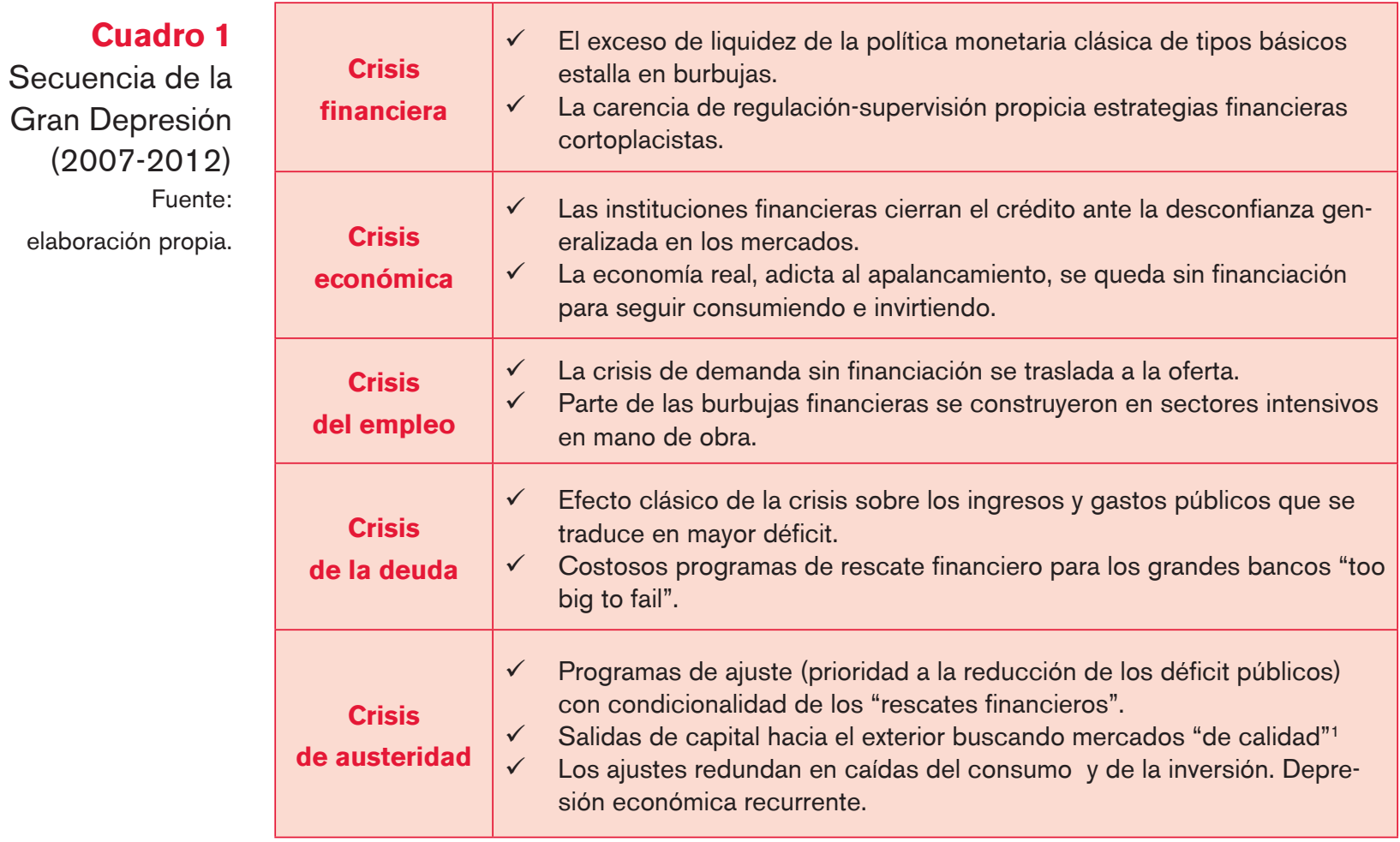

Dejando de lado o dando ya por conocido, el análisis de la crisis financiera internacional y su transmisión, con diferencias acusadas en los impactos sobre las diferentes economías nacionales, se puede observar como la economía española sufre, a instancias de tal depresión, un encadenamiento de shocks de singular magnitud interactuando entre ellos, que caracterizan, inicialmente, la particular idiosincrasia de la crisis española (García, 2012):

- se detiene abruptamente la entrada de capital financiero provocando el derrumbe del modelo financiero que se había venido practicando y el estallido de la burbuja inmobiliaria y a instancias de ello una situación crecientemente compleja para un sistema bancario con una fuerte concentración de riesgo en el sector inmobiliario (créditos a consumidores y a promotores);

- una brusca elevación del déficit fiscal a causa, fundamentalmente, de la caída en los ingresos fiscales y del ascenso del gasto público, arrastrado por los instrumento contra-cíclicos, de modo particular los denominados estabilizadores automáticos (subsidio de desempleo); 
- la economía se detiene y entra a un período en 2009-2011 en el que se alternan la contracción del crecimiento y la recesión, para sumergirse aún más en esto a lo largo de 2012;

- todo este conjunto de factores extiende la desconfianza en los mercados financieros sobre determinadas economías que están fuertemente endeudadas, bien en su sector público o bien en el privado, que traslada el riesgo al anterior a través de diferentes formas de aval, como resulta en el caso español.

De este modo, el estrangulamiento del crecimiento económico y la vuelta a la recesión -el FMI estima para 2013 que España reducirá el tamaño de su economía en otros 1.3 puntos porcentuales adicionales- causados por la imposición de planes de ajuste impuestos ("austeridad"), cada vez más severos, para cumplir con los objetivos fiscales, se convierten en una especie de "autoflagelación" para España y las economías periféricas de la UE. Se impide por este camino que tales economías desarrollen alguna posibilidad de crecimiento reduciéndose así, de forma progresiva, su dimensión económica y la del mercado europeo.

$Y$ desde que en mayo de 2010 se produjera el brusco giro hacia políticas de austeridad, cuyo principal objetivo consiste en ajustar las cuentas públicas (a costa de incrementar impuestos y reducir el gasto público), las economías europeas se han encaminado hacia una nueva fase de recesión más intensa, aún mayor que la pasada.

Ante la crudeza de la situación, todo indica que las perspectivas futuras no serán mejores. Como se observa en la gráfica 1 la depresión se propaga en forma de w, volviendo cifras negativas en la evolución del PIB y de mayor intensidad en el volumen de empleo. Los numerosos riesgos existentes centrados en el descenso de la demanda a nivel mundial, el auge del proteccionismo o la enésima complicación financiera que condiciona el futuro del euro, no permiten divisar en el mediano plazo la luz al final del túnel, impidiendo mejorar la actual situación de deterioro económico, político y social en España y en la mayor parte de Europa.

\section{Gráfica 1}

Variaciones trimestales del PIB y la ocupación en España (IIlt 1988 a llt 2012, en \% anual) Fuente: elaboración propia.

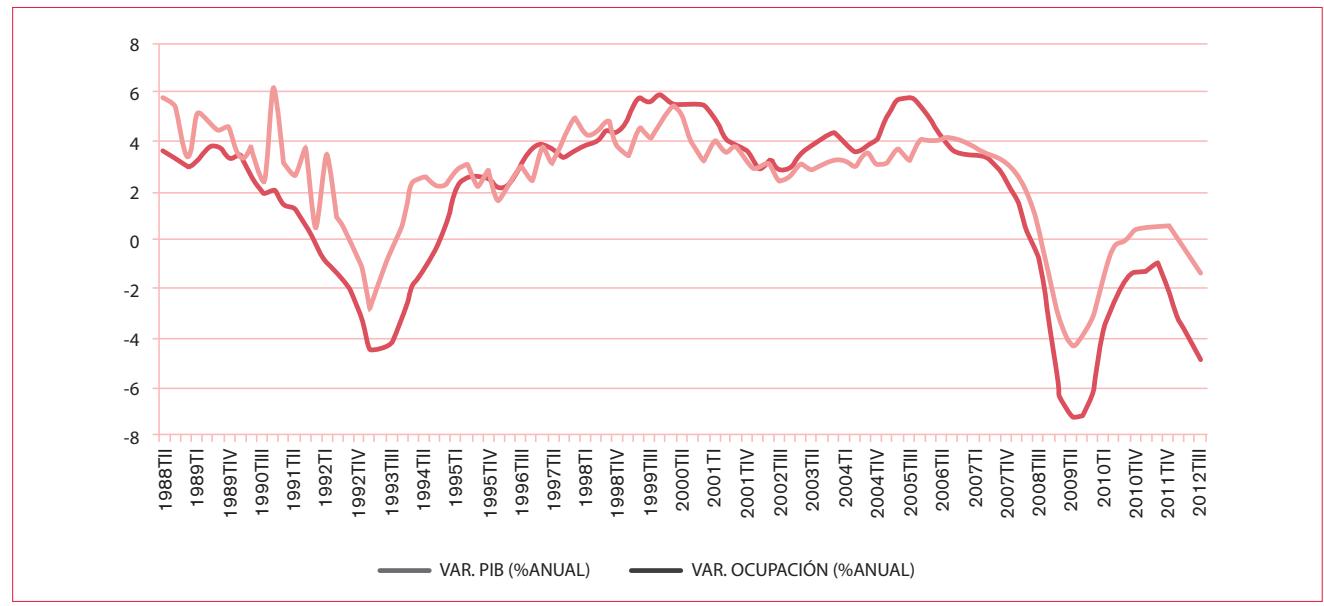

Pero veamos con algo más de detalle y análisis lo que ha ocurrido en el caso español.

La crisis de un modelo de crecimiento no sostenible para la economía española en el contexto de la Unión Monetaria. En el túnel de la moneda única 
De modo sencillo podríamos entender el éxito y el actual fracaso del modelo de crecimiento de la economía española si entendemos que en los últimos años se ha sustentado en el crecimiento de la demanda interna, apoyada en sectores no comercializables, y un desequilibrio procíclico del sector exterior de la economía. Ambas situaciones ponen de manifiesto carencias importantes en el desarrollo económico del país, cuyo tejido empresarial pierde competitividad de manera intensa desde la puesta en funcionamiento de la moneda única. Lo venía haciendo con anterioridad desde la integración de España en la UE, solo que a partir de la Moneda Única ya no hay opción a devaluaciones monetarias con objeto de ganar competitividad nominal, como se venía haciendo en la última década del pasado siglo.

La pregunta es qué ha fallado en la estructura productiva española para que en estos años no se haya avanzado sustancialmente en la perspectiva de una dinámica de crecimiento más sostenible, de modo que en una secuencia temporal larga no se haya podido converger con los países más avanzados de la UE, perdiendo en la fases depresivas del ciclo económico lo que se había avanzado en las alcistas.

A esta pregunta caben al menos tres tipos de respuestas que se ubican en planos diferentes. Primero el plano de la gobernanza de la moneda única, que condicionan a corto plazo la posible salida de la crisis, manteniendo en el desequilibrio creciente las cuentas publicas al tiempo que hunden más en la depresión la marcha de la economía española. Segundo, la propia estructura productiva, estancada en un modelo insostenible desde la perspectiva del crecimiento económico. Y, tercero, los errores manifiestos de la política económica, tanto en su dimensión monetaria, gestionada desde los ámbitos comunitarios, como en la fiscal, ubicada en el territorio institucional del Estado español, en su triple vertiente, central, autonómica y local.

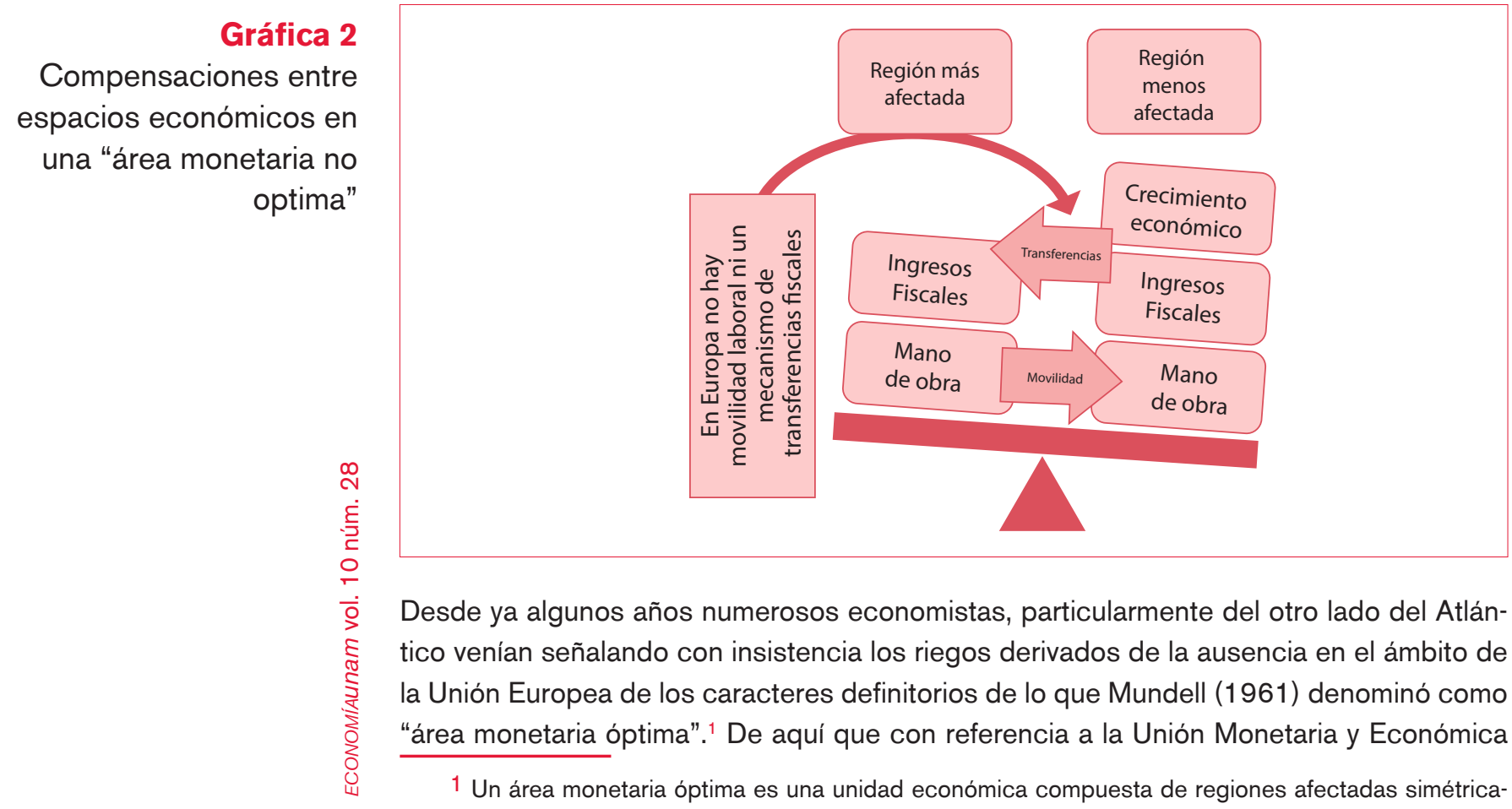


(UME) dichos analistas económicos ${ }^{2}$ insistieran, cuando se estaba gestando este nuevo espacio de integración monetaria en el seno de la Unión Europea, poniendo en cuestión la viabilidad y ulterior supervivencia de una unión monetaria, con intensas asimetrías entre los distintos espacios que componen el área y sin suficiente cesión de soberanía en otros ámbitos de la política económica (en materia fiscal, particularmente) que hiciera viable la transferencia de renta de unos espacios a otros para compensar las pérdidas derivadas de los ajustes de empleo y salariales en las economías periféricas o más débiles. $\mathrm{O}$ alternativamente, implementar una política fiscal expansiva en los países más dinámicos para arrastrar, mediante demanda externa, el crecimiento en las zonas más afectadas por el shock externo.

En un espacio de integración monetaria con acusadas asimetrías en cuanto a los niveles de competitividad, como ocurre en la UME, sin movilidad de mano de obra (o escasa) y con enormes restricciones para el manejo de la propia política fiscal (sometida al dictado de los objetivos de la política monetaria única) el resultado final de un shock externo se traduce casi de modo inmediato en desempleo y devaluación salarial, según las condiciones institucionales de cada país, en los países con menor nivel competitivo. Esta es la situación en la que se encuentra España, sin posibilidad de hacer frente con recursos comunitarios a los problemas derivados de la refinanciación de la deuda privada, convertida de facto en "soberana" por el mor del aval del sector público. La disponibilidad de recursos comunitarios se encuentra bloqueada por la posición político-ideológica de los países del centro-norte, con mejor posición competitiva en el seno de la UME, quienes se niegan a aportar recursos para abordar la crisis de la deuda, mancomunando ésta y abriendo espacios a una política fiscal común con financiación solidaria. ${ }^{3}$ Para una parte de la clase política de estos países tal estrategia acabaría en el ascenso de una corriente de opinión en sus respectivos electorados que abriría el camino a una especie de "síndrome de la Liga

mente por las perturbaciones económicas y entre las cuales el trabajo y los restantes factores de producción fluyen libremente. Una región considerada área monetaria óptima es aquella donde el uso de una moneda común no implica una pérdida de bienestar. Las características principales de un área monetaria optima son :

la movilidad absoluta de los factores productivos, sin trabas de ningún tipo: capital y trabajo,

perfecta flexibilidad de precios y salarios,

- shocks comunes, las regiones comprendidas dentro de un área se enfrentan a las mismas perturbaciones.

- en el caso de que la aplicación de las anteriores características perjudiquen más a unas áreas que a otras se pueden habilitar transferencias fiscales desde las regiones/países más ricos hacia los más pobres, para compensar los desequilibrios producidos por las asimetrías en los respectivos comportamiento económicos generadas a causa de un shock externo.

2 Curiosamente, incluso desde enfoques radicalmente opuestos, como pueden ser la perspectiva neoclásica o la postkeynesiana, venían a coincidir sobre la inviabilidad de un proceso de construcción de una Unión Monetaria en Europa sobre bases económicas tan asimétricas entre los distintas economías que concurrían al mismo.

3 Para Steinberg (2012:78) "la principal restricción a la que se enfrenta la consolidación del euro es la política interna de cada país. /.../ En países acreedores como Alemania esto supone una fuerte resistencia a convertir la unión económica y monetaria en una unión fiscal, por lo que el objetivo del gobierno ha sido hacer viable al euro con el mínimo coste para el contribuyente alemán, es decir forzando a los países de la periferia para que sean quienes realicen los ajustes necesarios para estabilizar la deuda soberana ....". 
Norte"(Bagnai, 2012) que pondría en peligro la propia continuidad de la UE como espacio supranacional. El problema es que la situación que están viviendo los países periféricos de la Unión Monetaria, sin perspectivas a corto plazo de soluciones comunitarias, significa también un riesgo de salida de los mismos del área monetaria de integración. El euro está pues sometido a una fuerte presión política interna, que se refleja también en su volatilidad de los mercados monetarios.

Recogiendo estas hipótesis, Bagnai (2012) ha desarrollado un trabajo empírico relevante, que aporta evidencia de que en el caso de España, como en otros países de la periferia europea (Italia, Grecia, Portugal o Irlanda), ha tenido lugar un ciclo minskyano de bonanza y crisis, ${ }^{4}$ sólo que en lugar de emerger como consecuencia del comportamiento de los agentes internos, se originó en un cambio exógeno en la política macroeconómica introducido súbitamente por la adopción del Euro, que fue equivalente a la adopción de un tipo de cambio fijo. Este hecho, analizado en el contexto de un modelo de crecimiento económico tipo Kaldor, de causación acumulativa, además de un efecto perverso en el sector financiero que se endeudó en Euros para dar créditos para inmuebles, operó como un shock macroeconómico, ya que la rigidez nominal cambiaria alimentó, a través de diversos canales -incluyendo el comportamiento de las exportaciones y del producto- un efecto negativo sobre el crecimiento de la productividad, lo que aceleró la divergencia en la competitividad/precio entre España y Alemania, por ejemplo (García, 2012a y Bagnai, 2012:3-4).

Es decir la presencia de España en una Unión Monetaria con asimetrias importantes en la dinámica económica de los diferentes países integrados, trajo como consecuencias, a partir de la integración iniciada en 1999:

- una pérdida notable de competitividad de su sector productivo respecto a los principales países de su entorno económico, lo que se refleja en un deterioro sustancial del equilibrio externo, puesto de manifiesto por el creciente desequilibrio de la balanza por cuenta corriente $y$,

- las necesidades de financiación de tal déficit coincidiendo con la convergencia de tipos de interés real con las economías más avanzadas de la UE, alimentan un proceso de intenso endeudamiento de los agentes económicos privados, que tras el estallido de la burbuja inmobiliaria, está poniendo en riesgo de quiebra a casi todo el sistema bancario español.

Sobre la primera cuestión se tratará más adelante, en relación con las carencias del sistema productivo español. Respecto al proceso de apalancamiento del sector privado conviene señalar también su incidencia en al primera cuestión, dado que con la complicidad acusada del sistema financiero español, tales recursos financieros provenientes del exterior en lugar de canalizarse hacia la inversión en actividades exportadoras o competidoras con importaciones, se orientaron prioritariamente hacia la construcción y venta de inmuebles, con elevados rendimientos a corto plazo a causa de las plusvalías generadas en la

4 "Minsky sostuvo que las crisis eran intrínsecas a los mercados financieros: cuanto más larga fuera la duración de los buenos tiempos, mayores serian los riesgos de los prestatarios" (The Guardian, Wednesday ,22 August 2007). 
burbuja inmobiliaria en expansión. Es decir, en lugar de priorizar el uso de esos recursos para hacer más competitiva a la economía española, se hizo lo inverso, se destinaron hacia actividades no expuestas a la competencia externa, como se ha señalado, porque a partir del shock que supuso la adopción del euro -muy similar a que si España hubiera adoptado un tipo de cambio fijo- la rentabilidad en la construcción se elevó y generó un ciclo minskyano de bonanza (García, 2012a). La elevada rentabilidad en este sector constituía un atractivo singular para los recursos financieros disponibles en los países con excedente comercial, el caso alemán, por ejemplo, que canalizada por su sector bancario se mostró ávido de oportunidades de inversión rentable.

El estallido de la burbuja inmobiliaria, llegado el sector a un elevado nivel de saturación de la demanda y enfrentándose a la creciente sequia de crédito hipotecario (a raíz de la desconfianza generalizada en el sistema financiero internacional, derivado del crack de las CDos y demás productos de la desregulación financiera estadounidense) arrastró consigo a una buena parte del sistema bancario español, con muy elevados niveles de concentración del riesgo en préstamos hipotecarios a compradores de viviendas y especialmente a promotores inmobiliarios (véase gráfica 3 ) que se ven abocados al cese de actividad a partir de 2007/20085. De este modo la cartera de activos de la banca, particularmente de las Cajas de Ahorros, ${ }^{6}$ se llenaron de inmuebles a medio terminar o terminados y terrenos para edificación, prácticamente sin valor de mercado. Técnicamente muchas de ellas entraron en situación de quiebra, no declarándola con el apoyo de la normativa contable española que les permitía mantener en sus balances el valor de compra y oscureciendo así la realidad financiera del país. No obstante, el conocimiento de esta situación en los mercados financieros supone el cierre de los mismos para la entidades españolas que no tienen donde acudir con el fin de refinanciar el enorme volumen de deuda acumulado.

A partir de este momento el sector público asumirá el reto de mantener el sistema bancario (con el argumento de "too big to fail") instrumentando diferentes medidas que básicamente han consistido en programas de rescate, con ayudas financieras a través del Fondo de Reestructuración Ordenada Bancaria (FROB), la nacionalización de las entidades más afectadas y promoviendo una fuerte concentración entre el resto. Medidas que impactan unas en el nivel del déficit y otras en el de endeudamiento público o simultáneamente en ambos. De ahí una vuelta de tuerca más al problema de la deuda soberana. ${ }^{7}$

5 El mayor del crédito hipotecario se fue concentrando en esta vertiente del negocio inmobiliario, tal como se deduce de la gráfica 3, en la que se observa desde el año 1998 una evolución dispar entre el total de préstamos hipotecarios acumulados y la de los concedidos para la adquisición de viviendas; la diferencia, básicamente los concedidos a promotores inmobiliarios, experimenta desde ese momento un crecimiento mucho más acelerado que los créditos a compradores, que suponen un riesgo relativamente menor para las entidades prestamistas.

6 Para un análisis del proceso autodestructivo experimentado por las Cajas de Ahorros españolas, que al principio de la crisis suponían más de $50 \%$ de los depósitos del sistema bancario. A finales de la década de los setenta del siglo pasado se inicio un proceso de liberalización del sistema financiero, que en lo que se refiere a las Cajas de Ahorro significó homologar su regulación, restrictiva en cuanto a la actuación fuera de su ámbito territorial, con los bancos comerciales. Ello propicio una importante expansión de tales entidades de ahorro, que en buena medida ha significado el principio de su fin. Una breve síntesis de dicho proceso hasta llegar a privatización/nacionalización de las Cajas de ahorros en el momento actual se analiza en Ruesga (2012b).

7 En la presentación de los presupuestos de 2012, el Ministro de Hacienda estimaba que la aporta- 


\section{Gráfica 3}

Evolución del crédito hipotecario total y a los hogares (en \% PIB)

Fuente: elaboración propia sobre datos Banco de España.

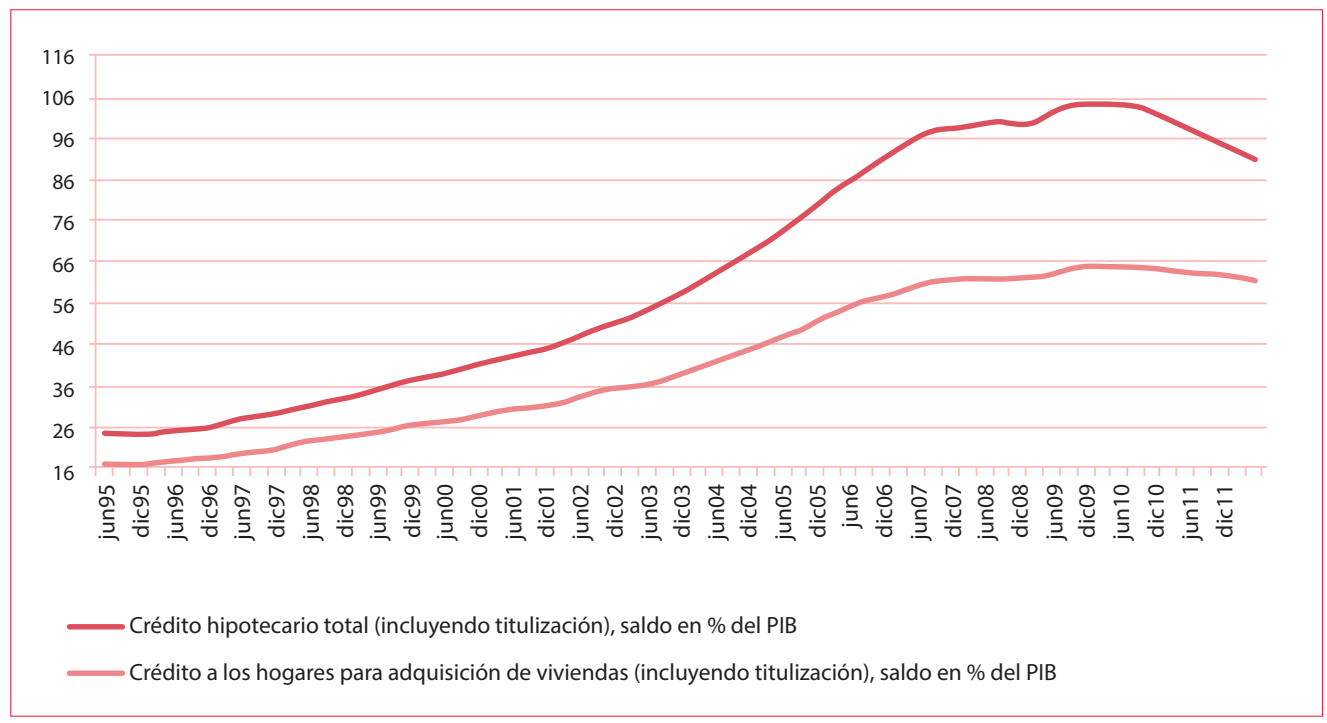

Y, a pesar de estos esfuerzos de reforma del sistema financiero español, la inestabilidad financiera no parece cercana a su fin. Porque, como concluye De Grauwe (2012:19), "una unión monetaria puede solo funcionar si es un mecanismo de mutuo apoyo y control. Tal mecanismo existe en una unión política. En ausencia de una unión política los países miembros de la eurozona están condenados a construir las piezas necesarias para completar tal mecanismo colectivo. La crisis de la deuda ha hecho posible completar unas pocas de tales piezas. Lo que se ha logrado está aún lejos de lo que resultaría suficiente para garantizar la supervivencia de la eurozona".

\section{Un modelo productivo insostenible ${ }^{8}$}

La segunda cuestión a analizar hace referencia a las deficiencias del sistema productivo español que se deducen de forma clara del análisis de la balanza de pagos del país. Entre 1996 el déficit externo por cuenta corriente de España se elevó desde 0\% del PIB hasta más de 9\% del PIB en el 2007. Este déficit externo fue financiado con un importante flujo de capitales financieros, procedentes gran parte de ellos de los bancos alemanes o de otros países europeos, que buscaban oportunidades de inversión para los excedentes de sus respectivas balanzas de pagos. Como se observa en la gráfica 4 tales necesidades de financiación del sector privado alcanzaron en el año $2007 \mathrm{el}$ $12 \%$ del PIB. Ello llevó a un fuerte endeudamiento de las familias y empresas españolas, que al calor del dinero barato se lanzaron a una desenfrenada carrera de consumo e inversión, particularmente, como se ha señalado más arriba, en el sector inmobiliario.

ción del erario público al rescate de los bancos, hasta esa fecha, ascendía a más de 20000 millones de euros, a mediados de 2012, sumando los costes de financiación del FROB para hacer frente a los problemas de solvencia del sector bancario, agudizados por las sucesivas reformas del sector fianciero decretadas entre 2010 y 2012. Quedan por inyectar 30000 millones de euros más para la banca nacionalizada y otros 35000 más para el resto de la entidades financieras, de acuerdo con la previsión del rescate bancario solicitado a la UE, que se fijó en 65000 millones de euros (cerca de 7\% del PIB).

8 Un análisis más detallado de este tema puede consultarse en Ruesga Benito y Da Silva Bichara (2011). Este epígrafe actualiza las conclusiones allí obtenidas. 


\section{Gráfica 4}

Necesidades de financiación de la economía española (en \% PIB) Fuente: Oficina Económica del Presidente del Gobierno (2011:90).

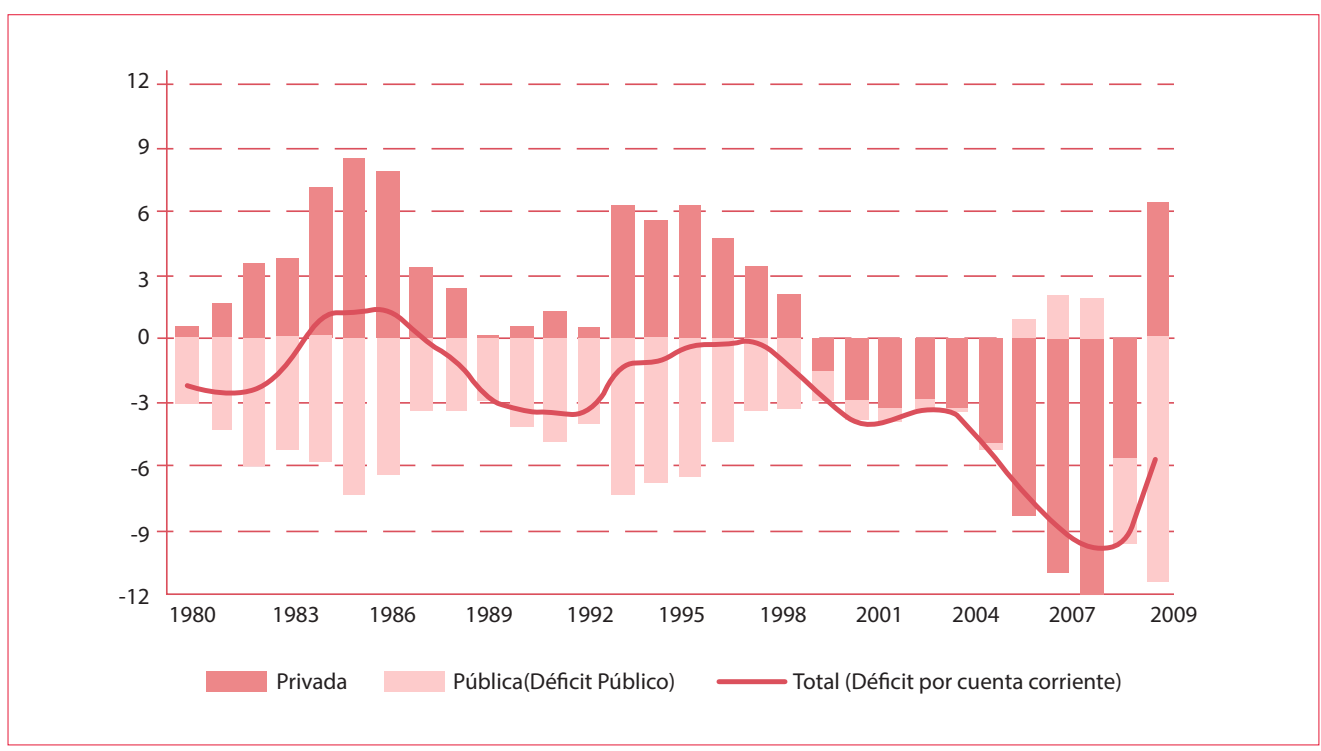

Las cifras ponen de manifiesto dos hechos relevantes que caracterizan el nivel de competitividad de la economía española, en un entorno comercial fuertemente concentrado en el ámbito de la Unión Europea.

a) Una pérdida paulatina de competitividad reflejada, como se ha señalado, en el crecimiento del déficit comercial en las fases expansivas del ciclo económico (gráfica 4). Lo que pone de manifiesto una elevada elasticidad renta de las importaciones que ensancha el déficit en las épocas expansivas y lo contrae, hasta llagar a anularlo en las recesiones. Lo que indica que el conjunto del tejido productivo español no es capaz de reaccionar ante los estímulos de la demanda agregada y las importaciones se encargan de satisfacer una buena parte de su crecimiento.

b) Un sector exportador que resiste razonablemente bien a los embates de la crisis, manteniendo la cuota de mercado y con crecimientos anuales en el periodo depresivo superiores a los que experimentan las ventas al exterior en el conjunto de la UE (en media anual). Lo que indica la existencia de carencias notables en la estructura empresarial española, particularmente en lo que se refiere a su tamaño. Unas centenas de empresas medianas y grandes, en tamaño, son capaces de arrastrar un tensión competitiva suficiente como para mantener la cuota de exportaciones en el mercado mundial a lo largo incluso del período de crisis, lo que ha permitido, junto a la caída de las exportaciones, una recuperación significativa de la balanza comercial. 


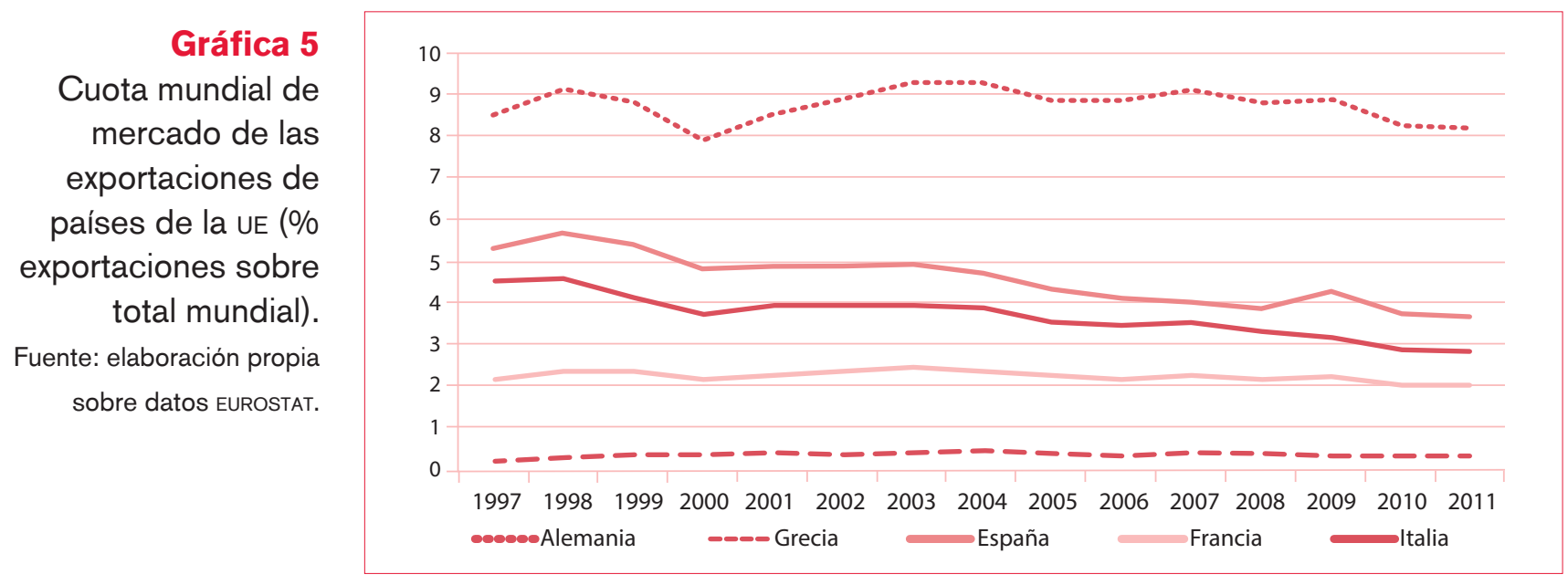

Los síntomas de agotamiento del modelo productivo vigente son múltiples, desde el fuerte estancamiento de la productividad laboral hasta el comportamiento altamente estacional del empleo en relación con el ciclo económico, generando oscilaciones en la tasa de empleo excepcionales en el contexto de los países desarrollados (véase gráfica 1). Y junto a ello, con diferentes enfoques y contenidos, se observa una visión casi unánime, tanto en el mundo académico como en el político, sobre la necesidad de modificar tal patrón productivo, para caminar hacia otro que se apoye en empresas más competitivas en el ámbito internacional, base de un crecimiento a largo plazo, sostenible y equilibrado.

Los problemas del sistema productivo español se concentran en su escasa capacidad para generar incrementos de la productividad de los factores, particularmente del factor trabajo como síntesis de los resultados del sistema productivo. $Y$ la crisis financiera internacional iniciada en el verano de 2007 ha puesto de manifiesto, aún más si cabe, los desequilibrios de la estructura económica española y de su patrón de crecimiento. ${ }^{9}$

El problema, sin embargo, no es básicamente sectorial, en todo caso la estructura sectorial pudiera ser el reflejo de lo que es el problema fundamental, la escasa productividad de todo el sistema productivo en su conjunto. ${ }^{10}$ Así pues, a la hora de plantearse un nuevo diseño del modelo productivo no debería tratarse tan sólo de propiciar cambios sectoriales en la estructura sino, prioritariamente, de promover e incentivar el desarrollo de las actividades con mayor capacidad de generación de valor añadido por unidad de inversión y con mayor efecto difusión del progreso técnico; es decir mejorar el crecimiento en la productividad de los recursos que se invierten en la actividad productiva.

${ }^{9}$ A este respecto conviene recordar que el comportamiento de las instituciones es fundamental para explicar el desarrollo sostenible a largo plazo. Véase, entre otros, Acemoglu et. al. (2004), Rodrik et. al. (2004), Easterly y Levine (2003) y North (1990). Sobre el debate teórico acerca de las cualidades institucionales requeridas para promover el desarrollo económico a largo plazo, particularmente en lo que se refiere al impulso de políticas industriales, véase Suzigan y Furtado (2006).

10 "Nuestro verdadero reto no es cambiar el modelo productivo sino mejorar la productividad del que tenemos. No se trata de cambiar la industria de automoción por la aeronáutica, ni la de construcción por las energía renovables. Nuestro desafío es hacer que turismo, construcción, automoción y resto de manufacturas y de servicios sean más productivos. Si lo logramos mejoraremos nuestras exportaciones y las ventas en el mercado doméstico, y la recuperación será más rápida y duradera" (Costa, 2009). 
El lento crecimiento de la productividad de la economía española es el reflejo de años de insuficientes incentivos al incremento de los procesos de innovación y de inserción de los mismos en el tejido productivo. La carencia de una política industrial continuada en el tiempo y con recursos suficientes constituye, desde la perspectiva del desarrollo económico, una importante laguna en el quehacer político de las autoridades económicas españolas.

Se asume, desde un enfoque sectorial de los problemas de competitividad, que incrementar la productividad en algunas partes del sistema productivo llevará ineluctablemente a aumentar el nivel medio de competitividad de la economía nacional. Sin embargo, desde un plano teórico se ha puesto de manifiesto una posible paradoja inherente a esa relación incremento de productividad-aumento de la competitividad, según la cual el resultado final del incremento de la productividad en algún sector de bienes comercializables podría llevar a una caída en la competitividad global de la economía a causa de un aumento generalizado de los salarios. ${ }^{11}$

Lo que puede llevar a la conclusión que, independientemente del comportamiento de los sindicatos ${ }^{12}$ en materia de demandas salariales, la dinámica de crecimiento de los salarios puede estar asociada con el fuerte incremento de la demanda agregada experimentado en la última década.

Gros y Alcidi (2010:7) insisten en esta dirección afirmando que "la perdida de competitividad medida en la periferia de Europa en la última década no debería estar por tanto adscrita a carencias de reformas estructurales o sindicatos poco razonables, sino más bien al boom en la demanda domestica alimentado por las facilidades de crédito barato para el consumo o la construcción, que condujo a un exceso de demanda de trabajo especialmente en los sectores más protegidos (por ejemplo servicios, aumentando, por ende, los costes salariales". ${ }^{13}$ Las reformas estructurales de mayor calado llevadas a cabo en España, tal como los diferentes episodios de reforma laboral, particularmente la decretada en febrero de 2012, no contemplan este tipo de análisis, insistiendo en modificaciones re-

11 Gros y Alcidi (2010:6) señalan a este respecto que hay al menos dos explicaciones a esta paradoja. La primera hace referencia a que: "un incremento de la productividad tiende a centrase en algunos sectores específicos; los sectores de bienes comercializables tienden a comportarse mejor que los de bienes y servicios no comercializables, en términos de productividad. Siguiendo un argumento estándar tipo Balassa-Samuelson, incrementos en la productividad en el sector de comercializables que justifiquen aumentos salariales en este sector pueden resultar en una pérdida de competitividad en el conjunto del país debido a que la inducción de un ascenso en los salarios también en los sectores de no comercializables, que suelen ser más importantes cuantitativamente hablando". Véanse a este respecto las estimaciones realizadas para la uME por Martínez Cañete, A. R. (2008).

12 Que en el caso español han apostado en los últimos años, incluso al margen del ciclo económico, por una política de moderación salarial sostenida que se ha apoyado en el diálogo social intenso mantenido entre los interlocutores sociales en lo que va de siglo, con la excepción del año 2009. Véase a este respecto Ruesga (2009) y Álvarez Peralta y Luengo Escalonilla (2012) y Huerta González (2012:4-6).

13 Por ello estos autores concluyen que "la política apropiada de respuesta a una pérdida de competitividad (que se juzga como perjudicial) debería concentrarse en la demanda agregada, no el desarrollo de los salarios o en aspectos específicos del mercado de trabajo. En el caso de España, por ejemplo, habría sido necesario frenar el ritmo de construcción de viviendas (subastando, por ejemplo, solo un número limitado de permisos de construcción), mas que tratar de entrometerse en el mercado de trabajo en medio del boom de demanda" (Gros and Alcidi, 2010:6). 
gulatorias que buscan un descenso generalizado de los costes salariales, sin alterar para nada las bases productivas del sistema (Ruesga, 2012a).

Lo cual lleva a considerar la enorme responsabilidad acumulada por los gestores de la política económica de las dos últimas décadas, alimentando el boom inmobiliario en detrimento de un modelo de demanda más acorde con las posibilidades del país, sin necesidad de recurrir a los flujos externos de capital necesarios para financiar el inmenso déficit externo acumulado en estos años. Tal reflexión es de singular importancia cara al futuro y en vista de la política económica a adoptar en la futura fase ascendente del ciclo económico, donde la tentación de inflar la bomba del consumo, al calor de bajos tipos de interés, puede hacernos volver a repetir errores del pasado. De aquí, que el enfoque de la política económica debiera estar marcado por la búsqueda de incrementos de productividad, equilibrados, en todos los sectores productivos, como ha señalado se ha señalado anteriormente.

En este sentido, el primer elemento a destacar es la baja tasa de crecimiento de la productividad del trabajo de la economía española frente a sus principales socios de la Unión Monetaria Europea. Esto significa que España está sufriendo pérdidas reales de competitividad frente a sus principales socios comerciales, lo que alimentaría todavía más el desequilibrio externo crónico que padece la economía española. Sólo en los últimos años, como consecuencia de la fuerte reducción del empleo a causa de la crisis económica internacional, se observa un comportamiento ventajoso para la competitividad de España. Sin embargo, este tipo de crecimiento de la productividad no es fruto del progreso técnico o reflejo de la mayor capacidad innovadora de las empresas españolas, lo que, por lo tanto, no estaría reflejando una mayor capacidad competitiva de la economía y además no se espera que se mantenga en el futuro. Se trata de un espejismo y no de un cambio significativo en las fuentes de crecimiento económico sostenido a largo plazo.

\section{Cuadro 2}

Tasa de crecimiento de la productividad del trabajo (horas trabajadas)

Fuente: Ruesga Benito y Da Silva Bichara (2011: 101) y elaboración propia con datos del EUROSTAT.

\begin{tabular}{|c|c|c|c|}
\hline & $1996-2000$ & $2001-2007$ & $2008-2011$ \\
\hline Zona Euro & 1.6 & 1.1 & 0.39 \\
\hline Francia & 2.1 & 1.4 & 0.17 \\
\hline Alemania & 2.0 & 1.5 & 1.18 \\
\hline España & 0.3 & 0.9 & 0.43 \\
\hline
\end{tabular}

En el análisis de esta característica estructural de la economía española uno de los primeros elementos a considerar es que España es un país de desarrollo tardío, por lo que la industria juega un papel significativo en el proceso del crecimiento de la productividad. Como señala Mochón (2008), "sólo la industria puede generar crecimiento estable y de alto valor añadido. La industria es el único sector en el cual son posibles aumentos rápidos y sostenidos en productividad. Además, todo desarrollo industrial exige una mejora del nivel tecnológico y de las capacidades de gestión". En definitiva se entiende que la producción de bienes tangibles, tiene una mayor capacidad relativa de absorción de las 
innovaciones y conversión de las mismas en productividad creciente para el sistema económico en su conjunto.

\author{
Gráfica 6 \\ Evolución de la \\ productividad total de \\ los factores en España y \\ Alemania \\ Fuente: elaboración propia \\ con datos de EUROSTAT.
}

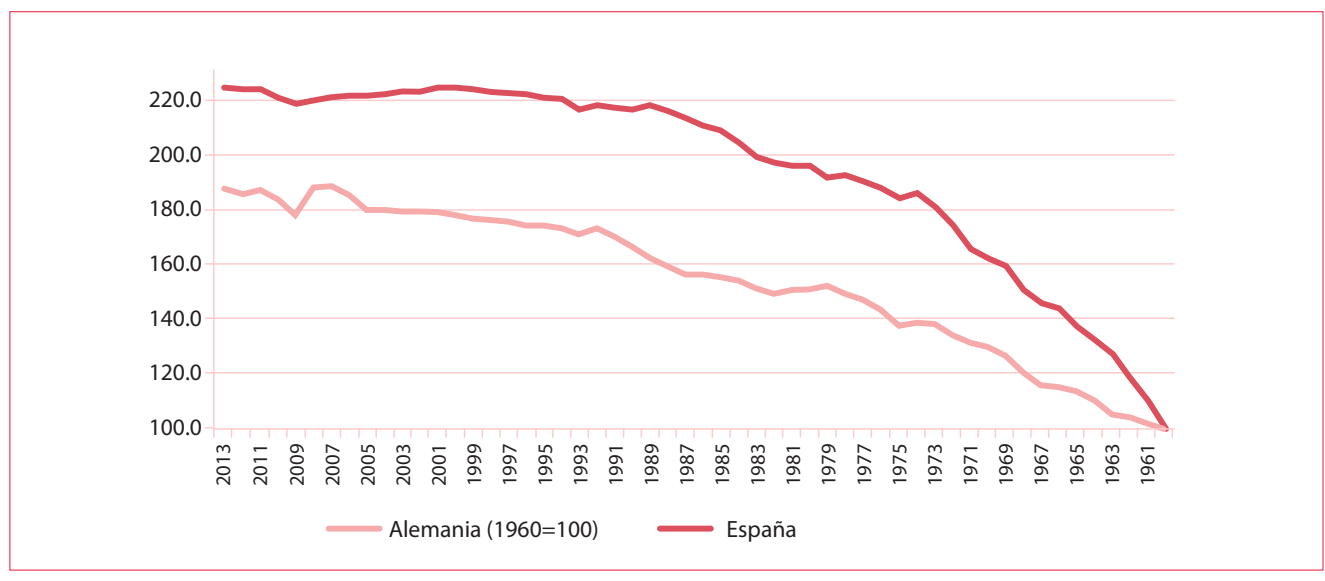

A la hora de identificar las razones del relativo retraso en la dinámica competitiva de la economía española, la Oficina Económica del Presidente del Gobierno (2011:92-105), José Luis Rodríguez Zapatero, se explicitaban una serie de carencias de tipo estructural, que se pueden sintetizar en: a) La escasa entidad relativa y el descenso en los últimos lustros del sector industrial; b) una baja intensidad relativa en la vocación exportadora de las empresas industriales (comparada con la media de las empresas industriales europeas); c) un significativo menor esfuerzo relativo en materia de I+D+i, particularmente en el último componente, la innovación y d) un reducido tamaño de las empresas industriales, lo que lastra la intensidad exportadora y el esfuerzo innovador de las mismas. Lo que ha ocurrido, por tanto, es que el desarrollo industrial ha sido comparativamente tardío y no ha llegado, en dimensión, a cotas excesivamente elevadas cuando ya comenzó a descender, contrastando con los niveles relativos de tejido industrial alcanzados en los países más desarrollados de nuestro entorno europeo antes de sumergirse en la sociedad postindustrial.

Así pues, cabría entender que el desarrollo económico español tiene todavía un recorrido que experimentar en cuanto a la promoción de la industria, obviamente en las vertientes de la misma con mayor capacidad de asimilar innovación. La asimilación de tecnología no es automática y, además, el grado o intensidad de tecnología que pueden ser asimilado depende de las características especificas de los diferentes sectores de actividad industrial y del tamaño de las empresas. Pavitt (1984) establece una taxonomía en la que categoriza los sectores industriales en función de la intensidad de tecnología utilizada, determinando a partir de ahí, una trayectoria de cambio tecnológico asociado a los diferentes sectores. Con esta perspectiva Pavitt establece cuatro categorías sectoriales industriales: basado en la ciencia, basado en suministradores especializados, intensivos en escala y sectores tradicionales.

Desde esta perspectiva, los sectores con mayor capacidad de promover el cambio tecnológico y el incremento de la productividad son aquellos basados en la ciencia o en suministradores especializados y, en menor medida, aquellos intensivos en economías de escala. 


Gráfica 7
Cuota de mercado
mundial de las
exportaciones e
importaciones de bienes
con alto contenido
tecnológico de Alemania
y España (\% sobre
expor e importaciones
mundiales,
respectivamente)
Fuente: elaboración propia
sobre datos EUROSTAT.

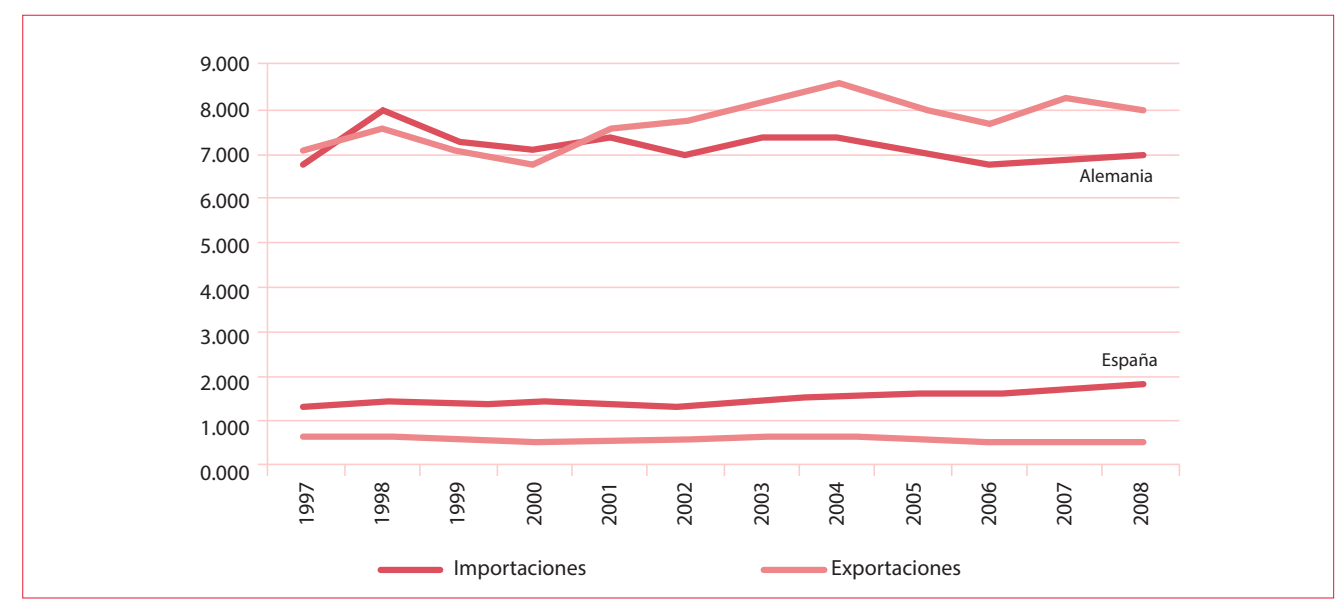

En este sentido es preciso contemplar como el tejido industrial español ha sido fuertemente dependiente de la importación de innovaciones y aún lo sigue siendo a pesar de un cierto crecimiento del esfuerzo propio en este terreno. Se están produciendo ligeros incrementos en inversión de I+D+i pero en términos absolutos aún estamos muy lejos de la media de inversión de la Unión Europea en su conjunto y, particularmente, de la antigua Unión Europea de los Quince. Se observa como la presencia de empresas españolas en el mercado de bienes con alto contenido tecnológico (gráfica 7) es bastante más reducida que su cuota mundial de exportaciones (gráfica 5), indicando la existencia de enormes carencias del tejido productivo español en el terreno de la incorporación de tecnologías avanzadas. La cuota mundial de exportación se sitúa en torno a $2 \%$, siendo cuatro veces inferior a la alemana, pero la cuota mundial de exportaciones de bienes de alto contenido tecnológico, entorno a $0.5 \%$, es 16 veces inferior.

A conclusiones similares se llega si se analiza de forma directa el esfuerzo inversor en innovación, en el caso español. La presencia relativa de las empresas como agentes innovadores es escasa, aunque es en su ámbito donde descansa la responsabilidad de incorporar las innovaciones al proceso productivo. El esfuerzo inversor del sector empresarial alcanza algo más de $50 \%$ del total de la financiación de I+D+i en el caso español, cifras lejanas aún a las que muestran los países europeos más dinámicos en la materia, donde la inversión empresarial es la preponderante, situándose en torno 75 y hasta $80 \%$ del global de los recursos invertidos en $1+D+i$. Esto es un freno importante al proceso de desarrollo español, en tanto que los esfuerzos del sector público y de otras entidades sin ánimo de lucro no se ven compensados con un dinamismo empresarial semejante en esta materia (Ruesga Benito y Da Silva Bichara, 2011:107).

Aquí radica uno de los límites más importantes al avance de la competitividad española, la existencia de un tejido empresarial con escasa vocación innovadora, vinculado a una estructura minifundista. Como se puede observar en la gráfica 8 , la empresa industrial española con más de 250 trabajadores en plantilla acumula poco más del $25 \%$ del total del empleo en el sector, cifras que le sitúan en el entorno de Italia, pero lejos de Reino Unido, que muestra cifras de $40 \%$ y más lejos aún de Alemania, con más de 50 por ciento. 


\section{Gráfica 8 \\ Distribución de \\ trabajadores en la industria según tamaño \\ de empresa}

Fuente: elaboración propia sobre Oficina Económica del

Presidente (2011:105).

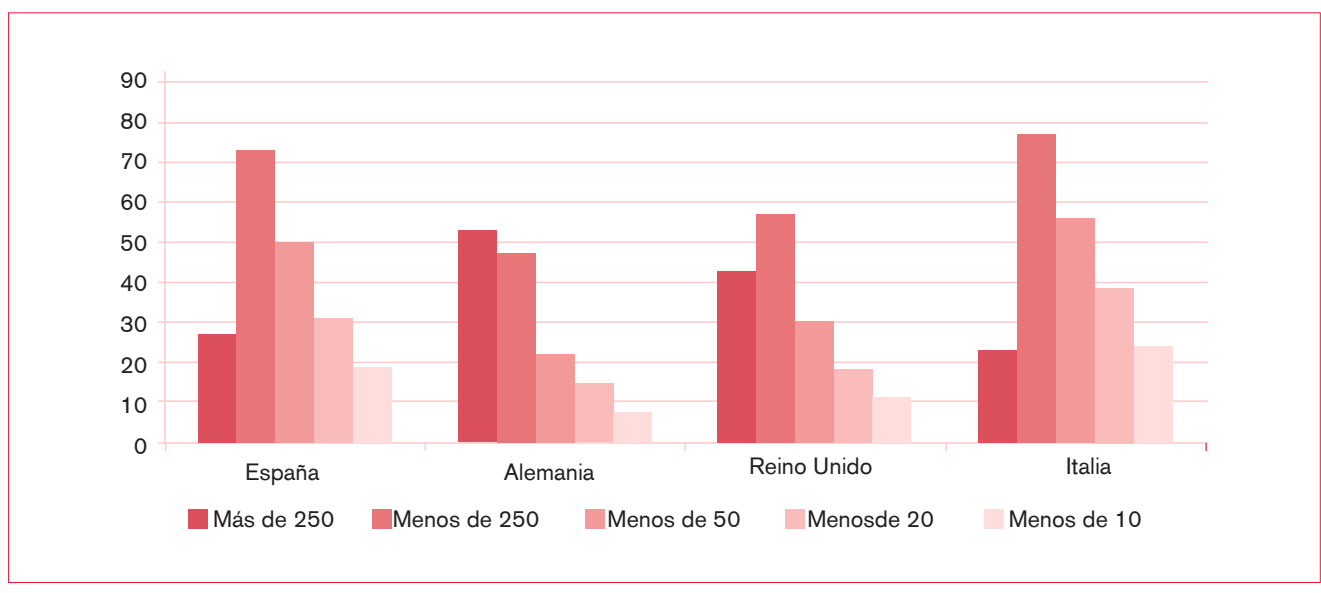

Adicionalmente, la ausencia de estrategias cooperativas interempresariales en materias de desarrollo e innovación tecnológicas bloquea las posibilidades de avance competitivo en el extenso territorio de las pequeñas y medianas empresas. Bien es cierto que en las fases expansivas del ciclo esta carencia parece no dejar una señal profunda en términos de crecimiento, pues apoyándose en el tirón de la demanda interna (el consumo privado, fundamentalmente) se especializa en sectores que no compiten con el exterior, en los cuales se pueden alcanzar elevados niveles de excedente bruto empresarial (léase el sector inmobiliario, por ejemplo). De ahí la dificultad en las fases bajas del ciclo para impulsar cambios drásticos en el tejido productivo hacia sectores más expuestos a la competencia internacional. La denominada internacionalización de la economía española se ha apoyado en un escaso número de empresas de servicios (en mucho menor medida industriales) que, en la terminología de Dunning, han explotado ventajas de propiedad cultivadas en los años ochenta en el propio país, en muchas ocasiones operando en condiciones de monopolio u oligopolio. ${ }^{14}$

El futuro de la economía española, en suma, aborda el futuro apoyándose en un tejido productivo con unas características que muestran enormes carencias ante la competencia internacional. La actual orientación productiva de la economía española no es la más adecuada desde el punto de vista del equilibrio externo y, por extensión, del crecimiento económico. Cuentas con un desarrollo escaso y de lento crecimiento de las industrias de alta y medía tecnología, lo que limita las posibilidades de aprovechar la propia demanda interna extensa en este tipo de productos industriales. Pero, al mismo tiempo, las carencias en materia de sectores tecnológicos, limitan también las posibilidades de desarrollo, en un entorno competitivo, de los sectores más tradicionales. Todo ello redunda en restringir las posibilidades de obtener mayores tasas de crecimiento económico a medio y largo plazo, de forma sostenida.

14 Véase para el caso de las empresas españolas que operan en América Latina, Ruesga y Casilda (2008). 
Remitiéndonos al mercado de trabajo, lo primero a considerar es como el "shock de demanda" ha afectado más o menos, en términos relativos a nuestro país respecto al entorno. $\mathrm{Y}$ a tal efecto conviene interpretar un aspecto de orden macroeconómico que determina la evolución cuantitativa y cíclica de las grandes cifras de nuestro mercado laboral. Se trata de comprender las características diferenciales de nuestro sistema productivo, que explicarán porque una determina caída de la demanda agregada se transforma en un impacto mayor o menor en términos de la dinámica del empleo y su traslación diferencial a la oferta de trabajo. En definitiva, la estructura productiva, en sentido sectorial y ocupacional, determina la elasticidad del factor trabajo respecto al producto y contribuye a explicar las oscilaciones del volumen de empleo a lo largo del ciclo económico (Palacio Morena, 2012).

Dicho en el contexto español habremos de explicar el alto diferencial que se registra en la economía española respecto a la media comunitaria en cuanto la volatilidad del empleo. En términos descriptivos y macroeconómicos la explicación resulta sencilla y coincide con la expuesta para otros países europeos de caracteres similares (Ruesga, 2010).

La abundancia de tejido productivo con escasa capacidad de innovación en todos los órdenes y una elevada demanda de trabajo no cualificado se materializa en cifras relativas poco relevantes de valor añadido generado por ocupado, en general y, en particular, en sectores como la construcción de viviendas, la hostelería u otros servicios (Ruesga Benito, S. M. y da Silva Bichara, J., 2011). Ello significa que en las fases alcistas del ciclo el empleo se eleva por encima de la cota de crecimiento del producto y lo contrario ocurre en el estadio depresivo del ciclo económico. Esto ocurrió en la depresión de los años noventa y en la subsecuente recuperación y eso está ocurriendo ahora (ver gráfica 2). La diferencia sustancial es que en aquel entonces el ciclo de recuperación se apoyó en sectores intensivos en trabajo sin que la demanda dirigida a estos estuviera saturada; en el ciclo actual, el componente diferencial ha sido que la explosión de la burbuja inmobiliaria ha puesto de manifiesto la imposibilidad de abordar la recuperación económica -particularmente del empleo- acudiendo al impulso de la actividad productiva en el sector: sencillamente la demanda a él dirigida está estancada y lo estará en los próximos años, no hay lugar pues a la generación de expectativas alcistas tales como las que en la segunda mitad de los noventa del siglo pasado y en la primera parte de la primera década del presente, alimentaron dicha burbuja. Todo ello con un impacto más intenso en lo que a destrucción de empleo se refiere.

Entre el segundo trimestre del año 2007, el momento más álgido en cuanto a volumen de empleo se refiere y el segundo de 2012 (diecinueve trimestres seguidos), el empleo ha descendido en cerca de tres millones de ocupados, es decir casi 15\% (exactamente 14.5), disminuyendo en media trimestral a un ritmo de 155 mil personas. Entre el III trimestre de 1991 y el I de 1994 (diez trimestres continuados), momentos de cenit y decadencia del empleo en el ciclo anterior, respectivamente, la ocupación descendió 1037 mil perso-

15 Una explicación más detallada sobre este dramático efecto de la crisis económica financiera se puede obtener en Ruesga Benito (2012). 


\section{Gráfica 9 \\ La destrucción de empleo en el ciclo, según colectivos (Ilt-2007-Ilt 2012)* de Ilt 2007 a IVt 2011.}

Fuente: elaboración propia sobre datos EPA

La consideración de estos impactos diferenciados en la oferta y la demanda de trabajo, permite definir el siguiente perfil

de la crisis del empleo que padece España, al compas de la crisis económica (cuadro 3 ).

Cuadro 3

Perfil de la crisis del empleo en España (2007-2012). nas, 7.9\% a razón de 103 mil por trimestre de recesión laboral. La situación actual refleja pues una crisis laboral de intensidad no conocida en el país hasta la fecha.

Avanzando un poco más en este tipo de análisis diferencial resulta de interés comprender la distribución del shock de demanda entre las diferentes categorías o segmentos de oferta que se puedan identificar, para tener una visión más profunda del impacto de la crisis en el mercado laboral. En este sentido la gráfica 9 sintetiza qué colectivos de ocupados han soportado en mayor cuantía relativa el descenso del empleo registrado en el transcurso de la actual crisis.

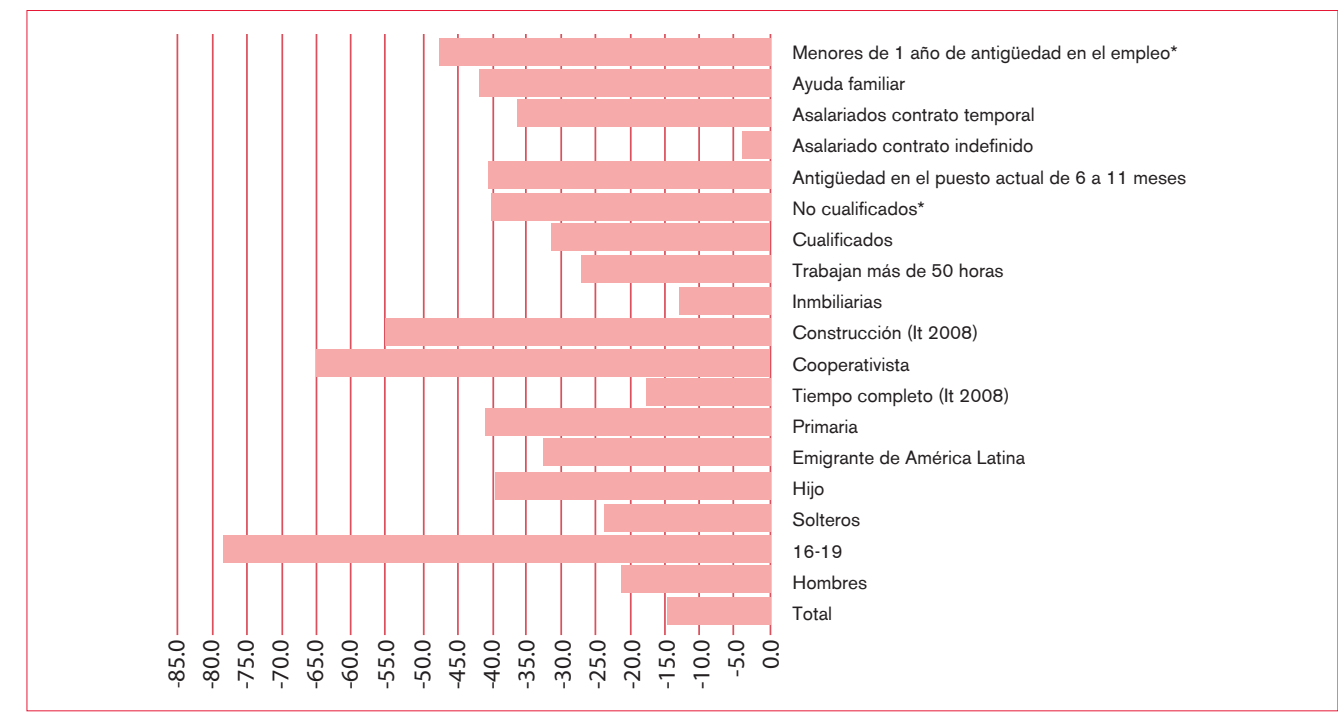

1. La demanda de trabajo se reduce a pasos de gigante, a consecuencia de la caída de la demanda agregada, particularmente la interna. El sostén de las exportaciones (industriales) no logra mantener ni mínimamente los niveles de empleo.

2. Es en la construcción donde la demanda de trabajo se contrae con más intensidad, lo que configura el perfil del desempleo.

3. Los jóvenes, son los primeros en salir del mercado laboral y los últimos en entrar.

4. El efecto desánimo, ante las condiciones adversas del mercado, afecta más a los varones y a los más jóvenes.

5. Los inmigrantes, particularmente latinoamericanos, son los más castigados por la crisis y retornan paulatinamente a sus lugares de origen,

6. Se está observando un cierto retorno a las aulas, con el consiguiente aumento del fenómeno de la sobreeducación. $Y$ un flujo creciente de salida al exterior de mano de obra joven y cualificada.

7. El ajuste laboral se concentra en la temporalidad al tiempo que avanza el trabajo a tiempo parcial.

8. Los costes laborales en descenso, mostrando, con cierto retraso, mucha flexibilidad a la baja, ante las condiciones del mercado.

9. El desequilibrio del mercado laboral no para de crecer desde el III trimestre de 2007, con diferentes velocidades, a lo largo de este período.

10. Tal evolución del mercado laboral arrastra tras de sí un fuerte incremento en la desigualdad en la distribución de la renta, con un incremento de los diferenciales medidos por el índice de Gini, de los más elevados de la UE.

Fuente: elaboración propia a partir de datos EPA (INE). 
Y como consecuencia de este devenir del mercado de trabajo, la distribución de la renta experimenta un intenso proceso de redistribución negativa, castigando principalmente a desempleados y jóvenes, al tiempo que la distribución funcional se desequilibra en contra de las rentas salariales. Así, el Fondo Monetario Internacional ha afirmado reciente mente que "España sufre uno de los peores deterioros absolutos en la distribución de la renta desde la crisis, debido principalmente al desempleo, aunque la existencia de rentas originadas en empleos informales pueden haber provisto de un limitado amortiguador" (IMF, 2012a:8-9), como se puede observar en la gráfica 10.

\section{Gráfica 10}

Impacto de la crisis financiera sobre la desigualdad en la distribución de la renta (2007-2010).

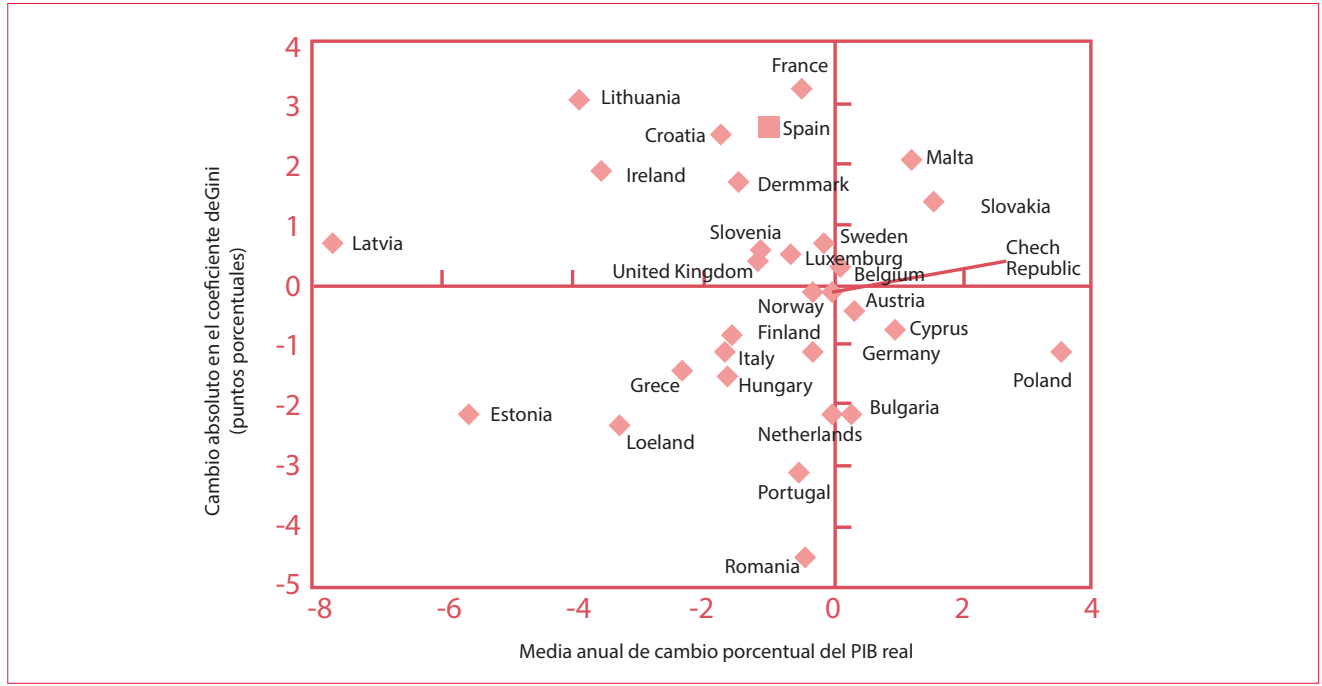

De igual modo, en la distribución funcional de la renta se observa un descenso acusado del peso relativo de las rentas salariales que pierden más de 3.5 puntos porcentuales en el corto espacio que transcurre entre el II trimestre de 2009 y el mismo periodo de 2012. Puede que este hecho, la elevada y creciente desigualdad en la distribución de la renta en España (y en otros territorios del mundo desarrollado), tenga una influencia decisiva en la persistencia de una elevada tasa de paro ${ }^{16}$ (o más ampliamente de trabajo indigno, según la terminología de la oIT, más no trabajo-desempleo).

\section{Los errores y carencias de la política económica}

Quizá no se ajusta del todo a la realidad hablar de "errores" en el manejo de los instrumentos de la política económica. Hay errores cuando el gestor no acierta a articular un conjunto de intervenciones sobre la marcha de la dinámica económica que permitan corregir la misma en una dirección determinada o cuando se equivoca al elegir los instrumentos

16 A este respecto Robert Skidelski, uno de los biografos destacados de John Maynard Keynes, señala: "La verdad es que no podemos continuar automatizando nuestra producción de manera exitosa sin repensar nuestras actitudes hacia el consumo, el trabajo, el tiempo libre y la distribución del ingreso. Sin dicho esfuerzos de pensamiento social creativo, la recuperación de la crisis actual será simplemente un preludio de más calamidades devastadoras en el futuro" (Skidelsky, 2012). Para un análisis más detallado sobre este fenómeno véase Skidelsky and Skydelsky (2012). 
adecuados o al ponerlos en funcionamiento. Pero que lo que ocurre, en ocasiones, es que los objetivos deseados sean políticamente inconfesables. $Y$ cuando esto ocurre, la política económica no se equivoca, tan solo es consecuente con tales objetivos no confesables y no lo es respecto a otros posibles objetivos explícitos, más con lo "políticamente correcto".

Si tuviéramos claro que los gestores de la política económica tratan de estimular el crecimiento económico y no lo consiguen, estarían errando en su modo de hacer. Pero si los objetivos son otros, posiblemente no este errando tanto.

En un primer nivel de análisis, se observa como desde el inicio de la crisis, allá por el tercer trimestre de 2007, los esfuerzos de las economías más desarrolladas se dirigieron, por un lado a frenar las posibles situaciones de pánico que pudieran provocar las quiebras de grandes bancos, y, por otro, a promover estímulos fiscales en un intento de frenar la caída del consumo y de la oferta productiva, con el corolario subsecuente en materia de empleo. En un primer momento, parecía que de las reuniones del G20 habría de surgir proyectos de cooperación internacional orientados a modificar la situación de los sistemas financieros, re-regulando lo que con anterioridad se había desregulado y, adicionalmente, impulsando políticas fiscales expansivas que hicieran frente al estancamiento de la economía real que ya se vislumbraba a finales de 2007. Las primeras reuniones del G20 en Washington y Londres, lograron un consenso inicial, al menos nominal, sobre la necesidad de recuperar y potenciar regulaciones que controlaran los excesos habidos en el sector financiero, de luchar contra paraísos fiscales y otras formas de evasión fiscal y poner freno a la caída en las tasas de crecimiento de la economía real. ${ }^{17}$ Pero nada de esto ocurrió. Bien es cierto que sí se produjo una cierta unanimidad de facto en cuanto a la necesidad de "rescatar" las entidades bancarias en situación de insolvencia, con diferentes modalidades según países, tras la experiencia de Lehman Brothers, interpretando que la laxitud de las autoridades norteamericanas ante la quiebra de esta entidad ponía de manifiestos la existencia de riesgos importantes de contagio y crisis sistémica que se derivaban de esta actitud (recuperando el viejo paradigma de "too big to fail").

En relación con esto, el rescate de los bancos en crisis, en España, se reaccionará tarde a la crisis latente de las entidades financieras. El gobierno del presidente Rodríguez Zapatero en un desacertado ejercicio de diagnóstico consideró que la existencia de una dotación de reservas anticrisis, obligada por el regulador, colocaba a las entidades de crédito españolas en una situación solvente frente a los efectos de la crisis financiera. La constatación de que los productos financieros derivados de las "subprime" no habían penetrado con intensidad en el territorio bancario español se superpuso a la evidencia de la existencia de un crack financiero interno provocado por el pinchazo de la burbuja inmobiliaria. De ahí que aquel gobierno "sacara pecho" por lo que entendía era un sistema

17 Desde la cumbre de Washington (14-15 noviembre de 2008) se han celebrado ya siete cumbres del G20, en Londres (2009), Pittsburg (2009), Toronto (2010), Seúl (2010), Cannes (2011) y México (2012). Ya desde la tercera (Pittsburg) se puso claramente de manifiesto que las buenas intenciones reformistas y de coordinación de políticas expansivas no pasarían de la mera declaración de intenciones, olvidando las criticas que en las dos primeras (Washington y Londres) se vertieron sobre las disonancias de las políticas económicas, particularmente las financieras, aplicadas con anterioridad al estallido de la crisis de la hipotecas "subprime". 
financiero altamente saneado, hasta que la evidencia puso sobre la mesa las deficiencias del mismo, particularmente en la Cajas de Ahorros. ${ }^{18}$

La política desarrollada en este terreno a partir de la evidencia manifiesta de la situación crítica de una buena parte del tejido de entidades crediticias se centró en: a) modificación de las normas del regulador bancario (Banco de España) sobre criterios de solvencia para las entidades crediticias (elevación de los ratios de "core capital", siguiendo propuestas comunitarias); b) impulso a un intenso proceso de concentración bancaria, particularmente entre las Cajas de Ahorros, en la creencia de que lograr entidades de mayor dimensión vacunaria mejor a éstas frente a los problemas de solvencia registrados (intento fallido en casos destacados como el de Bankia, en la que el proceso de fusión precipitó la crisis de la entidad resultante de la concentración); c) puesta a disposición de las entidades en situación crítica de recursos públicos a través de la creación de una entidad creada ad hoc, el FROB, bien a través de préstamos en condiciones preferentes o bien a través de la intervención directa, nacionalizando entidades (cajas de ahorros) que posteriormente serán privatizadas y $d$ ) finalmente acudiendo al rescate europeo para recabar fondo destinados a capitalizar, de nuevo, al sistema bancario. A tenor de numerosos analistas, aún con estas reformas y medidas financieras, el sistema bancario español aún no reúne condiciones de credibilidad frente a los mercados, lo que significa que difícilmente puede refinanciar su enorme deuda en los mercados exteriores y, por tanto, ha de seguir recurriendo a recursos públicos, del fisco español o del BCE. ${ }^{19}$

En el segundo aspecto reseñado, políticas de estimulo al crecimiento, destacan los escasos y desordenados esfuerzos realizados en hasta mayo de 2010 (Plan E en España, encuadrado en el llamado PERE, el Plan Europeo de Recuperación Económica), en el ámbito de la UE). ${ }^{20}$

18 El 9 de mayo de 2009 se anunciaba la inminente intervención por parte del Banco de España de la Caja de Ahorros de Castilla la Mancha. Tras ella han sido intervenidas otras más, hasta llegar a la nacionalización de una de las mayores, Caja Madrid, que en un proceso de "escapada hacia adelante" había constituido la entidad Bankia, fruto de absorción de otras Cajas de Ahorros, algunas de ellas en situación al borde de la quiebra.

19 En una reciente entrevista el Economista jefe para Europa de Goldman Sachs, Huw Pill, se ha mostrado muy pesimista con el futuro de España, indicando que "la inyección de liquidez (el rescate bancario aprobado por la UE) ayudará a España, pero el problema de este país es bastante más profundo. Para Huw Pill "a medio plazo es necesario limpiar los balances de los bancos españoles y probablemente reducir de forma significativa el tamaño del sistema financiero español". Y añade: "y la cuantía ofrecida para ese proceso [de recapitalización de la banca española] creo que también se comprobará que es inadecuada. Así que no creo que estemos asistiendo al final del partido" (El País de los Negocios, 21 octubre 2012). Es decir que el proceso de reforma del sistema financiero está incompleto.

20 El Plan Español para el Estímulo de la Economía y el Empleo o, en su forma abreviada, Plan E fue un conjunto de más de un centenar de medidas decretadas por el Gobierno de Rodríguez Zapatero en enero de 2009 y desarrolladas a lo largo de este año y del primer trimestre del 2010. Aunque el Plan E constaba de cuatro ejes de actuación principales, la mayor parte de los recursos se concentraron en cofinanciar obras a las administraciones locales, en la expectativa de frenar el imparable ascenso del desempleo. El gobierno dispuso 13000 millones de euros para la puesta en marcha de este plan y los ayuntamientos se convirtieron en los gestores fundamentales de la ejecución del programa. En conjunto el plan movilizó unos 50000 millones de euros, con escaso éxito frente a los objetivos de empleo y dinamización de la demanda agregada. Tras el giro de la política económica anticrisis, en mayo de 2010, el 
Pero, estas políticas de corte expansivo pasaron al olvido cuando en el año 2010, coincidiendo con una ligera recuperación de algunas de las grandes economías europeas, el objetivo de las políticas económicas se desplazó de forma nítida. En lugar de afianzar la recuperación de actividad económica (sobre todo, para que llegara a todos los países del continente), los esfuerzos se centraron en combatir los déficit públicos que se habían incrementado precisamente con el esfuerzo inicial de las políticas fiscales expansivas (además de por la actuación de los estabilizadores automáticos). El objetivo, por tanto, se tornó no tanto en la recuperación económica sino, fundamentalmente, en el reequilibrio de las cuentas fiscales.

A partir de aquí afloran para la economía española, de forma evidente y explícita si cabe, las limitaciones que introducía una determinada forma de gestionar la moneda única en un contexto recesivo. Como se ha señalado "los economistas keynesianos, neo keynesianos y post keynesianos siempre sostuvieron el argumento de que en situaciones recesivas y con trampa de la liquidez -en la que una tasa de interés muy baja no estimula la actividad económica- una política de fuertes recortes fiscales generaría una contracción recesiva porque en ese contexto el multiplicador fiscal sería más elevado y por consiguiente conduciría a fuertes caídas del PIB" (García, 2012b).

En este contexto queda el camino abierto a una política de "Quantitative easing", al estilo de lo que viene haciendo desde hace años la Reserva Federal de EE.UU., pero el BCE ha sido muy cautelosos en este terreno, siguiendo las pautas de los representantes alemanes, temerosos de que tales actuaciones generaran tensiones inflacionistas.

Y llegados a este punto, la Unión Monetaria, en su gestión actual, bloquea cualquier posibilidad de generar apoyos para frenar el problema de la deuda soberana, abriendo el camino a la crisis del euro, magnificando así lo que inicialmente era un problema de financiación de deuda (pública o privada) que requiera de un apoyo mancomunado para frenar los ataques especulativos de los mercados financieros. Las políticas de apoyo a la financiación de la deuda soberana, a través de los denominados "rescates" (créditos de organismos comunitarios a bajo tipo de interés para refinanciar deuda pública o privada que se vincula a la anterior), condicionadas a la realización de intensos ajustes en las cuentas públicas y de reformas estructurales encaminadas a reducir los desequilibrios de las mismas, principalmente, solo sirven para dar un pequeño margen de tiempo a las economías periféricas, pero no atacan el fondo del problema: en definitiva la desconfianza de los mercados financieros respecto delas economías fuertemente endeudadas y carentes de impulsos al crecimiento económicos (lastrados por la condicionalidad de los rescates y las políticas de austeridad que les sustentan) lo que les introduce en un círculo vicioso depresivo.

De aquí a la inestabilidad social y política que se derivan de estas políticas de austeridad, que redundan en recortes continuados en el gasto social, en un contexto de intensa depresión de la renta disponible de las familias. No es de extrañar pues que de aquí se deduzca que "los responsables políticos europeos han dado la batalla que se les pidió en la lucha por los mercados: una batalla contra el Estado, que finalmente resultó para ser una batalla contra la prosperidad y la paz en el continente europeo (Bagnai, 2012:25). Cabe

gobierno prolongó este tipo de actuaciones, pero ya con mínimos recursos financieros bajo el apelativo de Plan de Economía Sostenible (Fondo estatal para el empleo y la sostenibilidad local). 
por tanto concluir, en este sentido, que "la crisis ha demostrado que el "fundamentalismo del mercado" como se expresa en muchos de los tratados europeos así como en los "paquetes de rescate" que ahora se están proponiendo, han fallado" (ibídem).

Pero las carencias no acaban aquí. La centralidad de las políticas macroeconómicas, en la versión de corte neoclásico que vienen impulsando los organismos comunitarios, han dejado a un lado la ejecución de políticas industriales, tanto en el ámbito de las instituciones comunitarias, como en el de la propia actuación de las autoridades españolas. Ello significa que se ha dejado de lado cualquier intento de interferir en la estructura del sistema productivo, con el ánimo de modificar el modelo actual, agotando sus posibilidades de sostenibilidad en el futuro. Sería necesario sustituir este modelo de crecimiento apoyado en el uso intensivo del trabajo precario mal remunerado y poco cualificado impulsando una que sitúe en el centro de los incentivos públicos de todo orden la innovación, condición sine que non para incrementar la calidad y la productividad del trabajo. De ahí el protagonismo que habrían de alcanzar las políticas industriales, energéticas y medio ambientales y al mismo tiempo las políticas educativas para desbloquear los principales cuellos de botella que dificultan el cambio mencionado en España. así como un cambio en la aptitud empresarial que abra camino a procesos de cooperación, concentración y crecimiento que redunde en empresas industriales de mayor dimensión, con mayor propensión a la innovación y a la exportación.

$Y$, sin embargo, el crack financiero y sus secuelas $y$, sobre todo, la panoplia de políticas monetarias y fiscales articuladas para hacer frente a éste, con el añadido de las reformas estructurales ad hoc, han dejado fuera de cualquier consideración a las políticas industriales, denostadas en el discurso ideológico dominante en la Unión Europea.

\section{Bibliografía}

Acemoglu, D., Johnson, S. y J. A. Robinson (2004), "Institutions as the Fundamental Cause of Long-run Growth", Working Paper 10481, National Bureau of Economic Research".

Akerlof, G.A. y Shiller, R. J. (2009), Animal Spirits. How Human Psychology Drives the Economy and Why it Matters for Global Capitalism, Princeton University Press, Princeton, NJ.

Álvarez Peralta, I. y Luengo Escalonilla, F. (2012), "Competitividad y costes laborales en la UE", Principios, julio, pp. 24-44.

Bagnai, A. (2012), "Unhappy families are all alike: Minskyan cycles, Kaldorian growth and the Eurozone peripheral crisis", en Iniciativa para la Transparencia Financiera (ITF), Serie Lecturas, (www.itf.org.ar).

Corden, W. M. (1980), "Relationships between macroeconomic and industrial policies". The World Economy, vol. 3, No. 2, Oxford, Blackwell Publishing.

Costas, A., "Llamémoslo economía productiva", El País/Negocios, 29/11/2009, pp.4-5.

De Grauwe, P. (2001), The political economy of monetary union, Edward Elgar Pub, England.

Easterly, W. y Levine, R. (2003), "Tropics, germs and crops: How endowments influence economic development", Journal of Monetary Economics, 50, 3-39.

Easterly, William and Luis Serven, eds. (2003), The Limits of Stabilization: Infrastructure, Public Deficits, and Growth in Latin America, Stanford University Press and World Bank. 
European Communities (2009), Industrial relations In Europe 2008, Directorate-General for Employment, Social Affairs and Equal Opportunities, Office for Official Publications of the European Communities, Luxembourg.

García, N.E. (2012a), ¿Por qué Alemania insiste en mantener a España en un pantano?, en http:// augustoplato.blogspot.com.es/2012/08/por-que-alemania-insiste-en-mantener.html, 30 de agosto de 2012.

García, N.E. (2012b), ¿Más austeridad fiscal con menos crecimiento económico y empleo?, en http:// augustoplato.blogspot.com.es/2012/10/mas-austeridad-fiscal-con-menos.html\#.UH20-bQsxEQ), 16 de octubre de 2012.

Gros, D. and Alcidi, C. (2010), "Fiscal Policy Coordination and Competitiveness Surveillance: What solutions to what problems?", CEPS Policy Brief, Centre for European Policy Studies (http://www. ceps.eu).

Huerta González, A. (2012), "La insustentabilidad de la Unión Monetaria", Economía Informa, núm. 375-julio-agosto, pp. 3-26.

IMF (2012a), Spain, Country Report No. 12/202, July, International Monetary Fund.

IMF (2012b), World Economic Outlook, October, International Monetary Fund.

Laan, L. van der y Ruesga, S.M., "The spatial-institutional perspective on the labour market in Europe", en L. van der Laan y S.M. Ruesga (Eds.), Institutions and Regional Labour Markets in Europe, Ashgate, Aldershot, 1998, pp. 15-26.

Martínez Cañete, A. R. (2008), "Una reconsideración del modelo Balassa-Samuelson en la zona euro", Revista de Economía Aplicada, número 46 (vol. XVI), pp. 145-184.

Mundell, R. A. (1961), «A Theory of Optimum Currency Areas", American Economic Review 51 (4): pp. 657-665.

North, D. C. (1990), Institutions, Institutional Change and Economic Performance, Cambridge University Press, Cambridge, R.U.

Oficina Económica del Presidente del Gobierno (2011), Informe Económico del Presidente del Gobierno 2010, Madrid.

Ontiveros, E. (2012), "Revisionismos. El multiplicador fiscal", El País de los Negocios, 21 de octubre.

Palacio Morena, J. I. (2012), "El marco económico de la Reforma Laboral”, Documentación Laboral, Núm. 94, Vol. I, pp. 11-39.

Pavitt, K. (1984), "Sectoral patterns of technical change: towards a taxonomy and a theory", Research Policy, núm. 13: 343-373.

Rodrik, D. (2009), "Growth after the crisis" (http://www.hks.harvard.edu/fs/drodrik/).

Rodrik, D., Subramanian, A. y Trebbi, F. (2004), "Institutions Rule: The Primacy of Institutions over Geography and Integration in Economic Development", Journal of Economic Growth, Vol. 9, núm. 2, June.

Ruesga S. M. y Casilda, R. (2008), Impactos de las inversiones españolas en las economías latinoamericanas, Marcial Pons Ediciones Jurídicas y Sociales, Madrid.

Ruesga Benito, S.M. y Da Silva Bichara, J. (2011), "Fortalezas y debilidades de nuestro patrón de crecimiento. La necesidad de una nueva política industrial”, en José María Zufiaur (Coordinador), Hacia un cambio de modelo productivo, Grupo Editorial Cinca, Madrid (ISBN: 978-84-96889-89-7).

Ruesga Benito, S.M. (2009), "Un escenario de reforma laboral en España: modernización de la negociación colectiva”, Principios, núm. 17, junio, pp. 123-137. 
Ruesga Benito, S.M. (2012), "Crisis económica y mercado de trabajo", en José Ignacio Pérez Infante, Santos M. Ruesga Benito y Fernando Valdés Dal Ré (dir.), Relaciones Laborales en la crisis: España 2011, Madrid: Editorial Cinca.

Ruesga, S.M. (2012a), "La reforma laboral y sus implicaciones macroeconómicas", Ejecutivos, núm. 231, abril, pp. 10-11.

Ruesga, S. M. (2012b), "La tercera desamortización", Ejecutivos, núm. 234, julio-agosto, pp. 10-11. Skidelsky, R. and Skidelsky, E. (2012), How much is enough?, New York: Other Press.

Skidelsky, R. (2012), "EL paraíso perdido de la mano de obra" El País, 24/06.

Steinbeck, F. (2012), "La economía política de la reforma de la gobernanza del euro", Principios, julio, pp. $61-80$

Suzigan, W. y Furtado, J. (2006), "Política industrial y desarrollo", Revista de la CEPAL, 89: 75-91.

Tamames, R. (2000), Estructura Económica de España, Alianza Universidad, Madrid. 